\title{
The Effect of using Flipped Learning Strategy on the Academic Achievement of Eighth Grade Students in Jordan
}

\author{
Firas Ibrahem Mohammad Al-Jarrah ${ }^{1}$ \\ Ministry of Education \\ Jordan \\ Mustafa Ayasreh ${ }^{2}$ \\ Department of Education Technology \\ Jadara University, Associate Professor, Jordan
}

\author{
Fadi Bani Ahmad ${ }^{3}$ \\ Assistant Professor of Education Technology \\ Middle East University, Jordan
}

\author{
Othman Mansour ${ }^{4}$ \\ Department of Administration and Curriculum \\ Faculty of Educational Science, Middle East University
}

\begin{abstract}
This study aimed to reveal the effect of using the flipped learning strategy on the development of achievement and the trend towards it among eighth grade students in the English language subject in the Hashemite Kingdom of Jordan. The sample of the study consisted of a sample of eighth-grade students who study in government schools affiliated with the Directorate of Education in the Northern Mazar District in the Hashemite Kingdom of Jordan, and their number (50) students were distributed into two groups chosen randomly, one of them is a control group, and the number of its students is (25) and the other Experimental and the number of its students (25) students. Where the control group was taught using the usual method, the experimental group was taught using the flipped learning strategy. To achieve the objectives of the study, the researcher used the descriptive approach and the experimental approach (with a quasi-experimental design), and the study tools were: an achievement test and a questionnaire to measure attitude. The study materials also included educational software. The results of the study indicated that there was a statistically significant difference between the average scores of the group of students. The experimental group and the control group in the post application of the attitude scale in favour of the experimental group, and this indicates that the use of the flipped classroom strategy had an impact on developing students' attitudes towards it.In light of this, the researcher recommends several recommendations, most notably taking advantage of the standards and the proposed educational model in the current research in the field of English language learning, as well as the application of multimedia programs in the use of the flipped classroom strategy, to raise the level of students in the basic stage in academic achievement, and to expand the application of elearning And blended learning to improve students' attitudes towards using the flipped classroom strategy to learn English, holding training courses for teachers on the use of the flipped learning strategy, and employing modern technologies and social networks in the educational process.
\end{abstract}

Keywords-Strategy; flipped learning; academic achievement; eighth grade; introduction

\section{INTRODUCTION}

Educators are aware of the great impact of using technological innovations in the educational process due to the modern technological revolution of the increasing potential of computer, Internet and communicational applications, which were reflected in the educational process in all of its aspects, It also affected the level of student's learning, planning for teaching, educational content, teaching process Implementation and evaluation. Through using technological innovations in education, there are many teaching strategies that rely on the use of modern technology to provide target educational content to students outside the classroom, which make them deeply involved in the educational content in the classroom [5].

This era is considered the era of modernity, in which modern technologies have appeared, such as owning laptops, smartphones and tablets, and the integration of these collectibles in the educational process has become a modern necessity, so developed countries rushed to harness this technology to add excitement and suspense to the various elements of the educational process, such as the curriculum and effective means of communication between the teacher and the learner, taking into account the individual differences and meeting the special needs of each student, and providing the teacher and the learner with what was not available to them in the traditional educational methods before, so several innovative educational strategies and methods have emerged based on employing this diverse technology in the educational process, most notably inverted learning [11].

Inverted learning enhances the use of advanced technology outside the student's academic time, in order to achieve maximum student participation and learning during the traditional classroom, and to increase efficiency in building knowledge, collaborative work and discussion during the lessons. It seeks to reshape the educational process and change the usual role. It also combines face-to-face learning strategies with an internet-based learning strategy [4]. 
Flipped learning is a type of blended learning that uses technology to transfer lectures outside the classroom, where the idea of reflexing learning is based on reversing the learning tasks between the classroom and the home, This reversal of the educational process cannot be achieved without employing modern technology tools and integrating them into the educational process due to change. The characteristics, skills and conditions of the current generation of people, their possession of various communication tools and technical applications, help their ability to learn quickly and skillfully [14].

In flipped learning, the class and typical homework are transferred to another curriculum, where students watch short video lectures in their homes before attending school or during the time allocated for exercises, projects, or discussions [7].

English language and its four skills are in general considered as the means that a person uses to transmit his ideas and information, and it is an effective method, starting with speaking in the early stages of a person's life, so the individual must have self-confidence to speak in front of others and the desire to do so, He also must prepare for what he wants to talk about. Training and interconnectedness of sentences and ideas can help him to be understood, because language and its skills are distinguished methods that a person uses in his relationships with others, through these skills it is possible for him to practice persuasion processes and achieve vital goals in various fields. [13].

Based on the above, the two researchers conducted a study to find out the effect of using a flipped learning strategy on developing achievement and the trend towards it among eighth-grade students in English language subject in the Hashemite Kingdom of Jordan.

\section{A. Statement of the Problem}

The feeling of the problem stemmed from the researchers' acquaintance with previous studies and literature, which referred to the use of a flipped learning strategy in teaching, as well as from the experience of one of the researchers as a teacher of English language who is a $\mathrm{PhD}$ holder in educational technology.

Through the work of one of the researchers as a teacher of English language, it was found that there is a low achievement of students in English language subject, through their grades, which indicated the low level of achievement among eight students in English language subject in the Hashemite Kingdom Jordan.

\section{OBJECTIVES OF THE STUDY}

The current study aimed to:

1) Verify the effect of using a flipped learning strategy on the development of achievement among eighth grade students in English language subject in the Hashemite Kingdom of Jordan.

2) Verify the effect of using a flipped learning strategy on developing the attitude of eighth grade students in English language subject in the Hashemite Kingdom of Jordan.

\section{A. Research Questions}

The present study calls for the answers to the following research questions:

1) What is the effect of using a flipped learning strategy on developing achievement among eighth grade students in English language subject in the Hashemite Kingdom of Jordan?

2) What is the effect of using a flipped learning strategy on developing attitude among eighth grade students in English language subject in the Hashemite Kingdom of Jordan?

\section{B. Significance of the Study}

The importance of the study is represented in the following:

1) Explaining the advantages and how to employ flipped learning strategy in learning that focuses on the learner's activities.

2) Explaining the role of both the teacher and the learner in the learning environment based on the flipped learning strategy.

3) Raising the level of eighth grade students 'achievement in English language subject, and using it in many life situations.

4) Developing students 'positive attitude towards learning, which qualifies and motivates them to continue the process of learning English language and to contribute to the elevation and position of the Hashemite Kingdom of Jordan.

5) Upgrading eighth grade students in educational and information technology skills.

6) Informing officials on the matter of curricula and teaching methods to the importance of the flipped learning method as a method within modern teaching methods that can be used in developing motivation to learn the skill of conversation, as this type of learning enables students to rewatch the explanation of a certain point more than once, or to accelerate display to reach what is required, with the possibility of viewing through a computer or mobile devices, that allows engaging in the educational process at any time.

\section{Limitations of the Study}

The current research is confined to the followings:

Human Frontiers: A sample of (50) students of the eighth grade who study in government schools affiliated to the Directorate of Education in the ALMazar ALShamali District in the Hashemite Kingdom of Jordan.

Substantive boundaries: A unit of the English language course for the eighth grade in the Hashemite Kingdom of Jordan.

Spatial boundaries: The current study was applied in the schools affiliated to the Directorate of Education in the ALMazar ALShamali District.

Temporal boundaries: The current study was applied in the first semester of the academic year 2020/2021. 


\section{THEORETICAL FRAMEWORK OF RESEARCH}

The tremendous development in information and communication technology has contributed to learning, so we have to pay attention to the educational process, it is imperative to change teaching strategies to keep pace with this development. It builds the student's personality, so it will better to continue from the basic lower stage until it grows with students in all stages of their lives [1].

The idea of flipped learning came after reviewing a recent book in the West called "flipped learning. The first signs of this strategy began to appear in (2006), and then it expanded little by little until it became widespread in many countries and it was associated with the concept of flipped classrooms or flipped learning, and the idea of learning. Inverted class is an old idea, but it imposed itself extensively with the development of technology tools, but researchers disagreed about the names of flipped learning, such as flipped learning or inverted class, and some students applied it in university learning, and some students applied it in the three educational stages, and some considered this learning just a heresy, but it will be applied. Mahalla [15].

Flipped learning is defined as "an educational model in which lecturing and homework are reflected in all its forms and is a form of blended learning that includes the use of technology to benefit from learning in the classroom" [9].

Flipped learning is an educational strategy that combines the use of modern technologies such as web applications, videos, and e-books, so that they are available to the student at home; Where the student practices direct individual learning and turns the classroom tasks into interactive learning activities in small groups in the classroom to implement the educational activities and tasks assigned to the student [8].

\section{A. Advantages of Flipped Learning}

Flipped learning is characterized by being able to change constantly to meet students' needs, it is mixed with fun and vitality, with little explanation within the classes, A lot of cooperative learning, discussions and educational projects, ensure good use of lecture time, and allow more time for inquiry-based activities. The teacher takes advantage of the class more for guidance, motivation and assistance. he builds stronger relationships with the students, the student turns into a searcher for his information sources, which enhances critical thinking, self-learning, building experiences, communication and cooperation. Flipped learning provides immediate feedback to the student from teachers at the time of the lecture [17].

The flipped learning strategy keeps pace with the digital age and modern technologies and entrenches the digital culture instead of fighting it, or resisting it. It allows learners to use their mobile phones, participate in the performance of activities with each other, interact, and communicate with the teacher at the same time, It helps learners who have other connections, as job or family links, to contribute to the provision of content through the educational video, and the internet, The student can watch it at the time and place appropriate for him, to help learners who are late in the course of studies. The teacher has a lot of time in the reverse learning strategy, where he follows up the learners who are late for studies and who face problems or difficulties, it also helps them to solve and overcome them, and develop plans to address them [10].

It is also providing class or lesson time for activities instead of consuming it in the explanation that may be forgotten. The flipped classroom employs sensory learning that has proven effective in learning, so that learning is active outside the school and active in the classroom, It makes the learner as the centre of the educational process, activating strategies for brainstorming, simulation and working in groups [2].

\section{B. Steps for Flipped Learning}

The teaching process is done by learning flipped through clear steps that the teacher can take, most notably [5]:

The process for teaching a flipped learning went through some steps that the teacher should undertake such as: determining the objectives of the lesson, where the teacher creates a realistic picture of the lesson and the results that are required to be achieved at the end of the lesson, then he begins to search for educational material, including videos and animations that help in the delivery of the knowledge and skills required to be clarified to students, which helps students to understand the topic, or prepare it to serve a topic. The lesson and the use of clear and direct language for students to clarify the objectives and basic concepts in the lesson let the student return to these references whenever he wants with ease. An index of the contents is also made to make it easier for students to move between the important topics they need, in addition to trying to involve parents in the follow-up processes for lessons at home while students work on them, and the teacher holds discussion and brainstorming sessions about what the student learned, so that he takes feedback from his colleagues, which helps him to rebuild knowledge in a logical way with the need for the student to be convinced of what he learns, This process may be a starting point for a new project that the student himself plans to implement and implement.

\section{Implement the Experiment}

The proposed program was applied to the students of the experimental sample for research as follows:

1) The researcher clarifies to the students the study sample the nature, the objectives and importance of the educational program.

2) Distributing the educational program on a CD-ROM, and giving copies to each student from the study sample, after making sure that each student owns a computer at his home.

3) The students of the study sample watch the required lessons on the CD outside the classroom (at home) and take notes, questions and inquiries about the difficult concepts they encountered while watching the lesson.

4) After that the researcher met with the research sample students in the classroom, where at the beginning of the class the researcher asked some questions about the topic of the lesson that the students watched outside the classroom to 
confirm their understanding of some basic and important concepts.

5) Then, the researcher received notes, questions and inquiries from the research sample about what is difficult and unclear for them, then the researchers explained it and answered questions and inquiries.

6) After that and at the end of each lesson, the researcher made sure to review the lessons that were given to the students of the research sample.

7) After the students return to the research sample, they search, browse, develop their knowledge and review the lessons they have learned, and then they begin to see the following lessons. These steps continue until the end of the educational program. During that period, the control group was receiving educational lessons using the traditional method.

\section{EMPIRICAL STUDIES}

The author in [19] conducted a study aimed at comparing active learning in traditional classes and active learning in flipped classrooms. The sample of the study consisted of (28) students in mathematics major at Ohio University, USA. The descriptive analytical approach was used in which data were collected through observations and personal interviews with students, the results showed students' satisfaction with the educational process using the flipped classroom, and they showed a deeper understanding of the concepts of content and retention in the flipped classroom compared to the traditional classes.

in [18] study aimed to investigate the effect of using flipped learning on the algebra subject at the University of Colorado on the students 'educational attainment, where the quasi-experimental design was used. The experimental group consisted of (135) male and female students distributed over five divisions studying algebra using the flipped learning model. The control group consisted of (166) male and female students distributed over six people taught algebra in the traditional way of lectures and homework. The results of the study showed that there were no statistically significant differences in the grades of the students of the two groups, but the results of students in the subjects in which the flipped learning was applied was slightly better than the students in the subjects that studied in the traditional way, and the trainers were in the classes that in which the flipped learning was applied, who had previous experience with verification-based learning, and cooperative learning had statistically significant differences on the final test results.

\section{A. Commenting on Previous Studies}

The studies dealt with topics related to flipped learning, as the strategy of the flipped classroom, have shown a developing in the level of achievement, such as the study of [13] and the study of [6], [21], [13], identified the effectiveness of an educational environment based on the inverted class in developing grammar and direction. [14] Identified the effect of using a flipped learning strategy on achievement and cognitive retention in teaching mathematics skills. The study of [3], aimed to identify the effect of using flipped learning in increasing achievement and developing the skills of the electronic operations course for learning resource centers. The study of showed the effect of using the flipped classroom strategy in teaching the subject of interpretation on academic achievement, The study of [19] aimed identify the evaluation of the effect of the flipped classroom model on achieving academic achievement [20]. Study aimed to compare active learning in traditional class's active learning in flipped classrooms [18]. Study aimed to find out the effect of using flipped learning in algebra [16]. Study indicated building an educational program using multimedia and investigated its impact on developing speaking and writing skills, the study of [12] showed the degree to which secondgrade students possess some basic speaking skills in the light of the educational content. The current study is similar to previous studies in terms of a quasi-experimental approach such as [13] study [3] [6], [14], [5] but it is different in terms of the sample with the study of [3], the [20] study and the study [19]. The current study is the only study that includes the effect of using a reverse learning strategy on developing achievement and the trend towards it among eighth grade students in English language subject in the Hashemite Kingdom of Jordan.

\section{MEthodology}

\section{A. Research Methodology}

The researchers used the following two approaches:

1) Descriptive Analytical Approach by reviewing studies and literature related to research variables and preparing research tools.

2) Experimental Approach in order to measure the effect of the independent variable represented by (the inverted learning strategy) on the dependent variable (achievement and the trend towards an excise learning strategy) among eighth grade students in the English language subject in the Hashemite Kingdom of Jordan.

\section{B. Research Variables}

1) The independent variable: the teaching strategy and it has two levels:

2) The experimental group that was taught using a flipped learning strategy.

3) The control group that was taught in the traditional way.

4) The dependent variable:

a) Achievement in English language.

b) The trend towards a flipped learning strategy.

\section{Research Tools}

1) An achievement test to measure the achievement of the research sample for English language subject.

2) A trend scale to know the students' attitudes of the research sample in the direction towards a flipped learning strategy.

\section{The Research Sample}

The research sample consisted of 50 students randomly, divided into two experimental groups (25) students and a control group of (25) students. 


\section{E. Research Procedures}

The following is a summary of the research procedures:

1) To answer the first question:

2) Preparing an achievement test in English language subject from the eighth grade curriculum and calculating its validity and reliability.

3) Selecting the research sample from the eighth grade students in the Hashemite Kingdom of Jordan, and it was divided randomly into two groups: one group studying by using the reverse learning strategy, and the other group studying by using the traditional method.

4) The pre-application of the achievement test.

5) Conducting the basic research experiment where the experimental group is studying the learning content through the reverse learning strategy and the second in the traditional way.

6) The post application of the achievement test.

7) Interpret the results and make recommendations and suggestions.

\section{F. To Answer the Second Question}

1) Preparing the search tool represented by the trend scale.

2) Selecting the research sample from the eighth grade students in the Hashemite Kingdom of Jordan, and it was divided randomly into two groups: one group studying by using the reverse learning strategy, and the other group studying by using the traditional method.

3) Pre- application of search tools.

4) Conducting the basic research experiment where the experimental group is studying the learning content through media, and the second in the traditional way.

5) The remote application of the search tool.

6) Interpret the results, and make recommendations and suggestions.

\section{G. Measuring Tools}

After completing the implementation of the research experiment, the researchers re-applied the achievement test and the trend scale on the two research groups, the experimental group and the control group, to measure the degree of gain in their achievement of English language subject, and to know their attitudes towards reverse learning, after studying the educational content of the English language course using the reverse separation strategy. Then, after completing the application, the researchers corrected the test items according to the correction key prepared for that and monitored the students 'grades, and also monitored and collected the marks on the five axes of the trend scale, In order to statistically treat them to verify the correctness of the hypotheses, and analyze and draw conclusions.

\section{RESULT}

The validity of the first hypothesis test and its text:

There is a statistically significant difference at the level of (0.05) between the mean scores of the experimental group and the control group students in the post application of the cognitive achievement test in favor of the experimental group.

To answer and test the validity of this hypothesis, the arithmetic averages, standard deviations and results of (T) test were extracted for independent samples to verify the statistical significance of the differences between the two research groups. The two groups were compared on two levels, namely (grammar and vocabulary) and cognitive levels (understanding, remembering, and applying) according to the course criteria.

It is evident from the Table I that there are statistically significant differences between the experimental and control groups in the items dimension in favour of the experimental group, as the calculated value of $t$ is greater than the tabular $t$, and this value is a function at the level (0.01). It can be inferred from these values that teaching using the reverse learning strategy is effective in improving the achievement of eighth grade students in the English language subject in Jordan in the vocabulary of English language.

Table II shows the clear difference between the averages of the experimental group and the control group in the dimension of the Grammar, where the average of the experimental group was (10.2400), while the average of the control group was (6.9200). This difference is significant at the level of (0.01) and this is evident from the value of t. The tabular $\mathrm{d}$ is greater than the calculated $\mathrm{t}$. The following tables shows the differences between the experimental and control group in the post application at the level of English grammar.

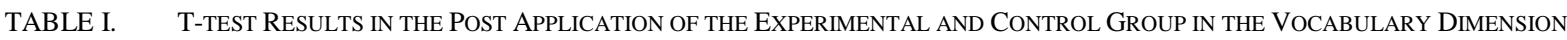

\begin{tabular}{|c|c|c|c|c|c|c|c|}
\hline \multicolumn{3}{|c|}{ T-test } & DS & M & N & The group \\
\cline { 1 - 5 } Indication & df & T & & Parts \\
the test & Vocabulary \\
\hline \multirow{2}{*}{0.01} & 48 & 4.235 & 2.5703 & 9.2400 & 25 & Experimental \\
\cline { 4 - 7 } & & & 2.0025 & 6.4800 & 25 & control groups \\
\hline
\end{tabular}

TABLE II. The ReSults of THE T-test IN THE Post APPLICATION OF THE EXPERIMENTAL AND CONTROL GROUP IN THE DimENSION OF THE GRAMMAR

\begin{tabular}{|c|c|c|c|c|c|c|c|}
\hline \multicolumn{3}{|l|}{ T-test } & \multirow{2}{*}{ DS } & \multirow{2}{*}{ M } & \multirow{2}{*}{$\mathrm{N}$} & \multirow{2}{*}{ The group } & \multirow{2}{*}{$\begin{array}{l}\text { Parts } \\
\text { the test }\end{array}$} \\
\hline Indication & df & $\mathrm{T}$ value & & & & & \\
\hline \multirow{2}{*}{0.01} & \multirow{2}{*}{48} & \multirow{2}{*}{4.661} & 10.2400 & 2.7880 & 25 & Experimental & \multirow{2}{*}{ Grammar } \\
\hline & & & 6.9200 & 2.2158 & 25 & control groups & \\
\hline
\end{tabular}


Table III shows the high average of the experimental group compared to the control group. This difference between the two averages indicates that there are differences between both groups in favour of the experimental group. The value of $\mathrm{T}$ was 5.162, and this calculated value is greater than the tabular value. It is a function at the level of 0.01 . Below is an illustration showing the difference between the experimental and control groups.

It is evident from the Table IV that there are differences between the averages of the experimental and control group in remember of the experimental group. It is also evident from the table that the calculated value of $t$ is greater than the tabular value of $t$, and this value is a function at a significance level of 0.01. The following table compares the averages of the experimental and control group at the level of understanding.

The value of $\mathrm{t}$ in the Table $\mathrm{V}$ shows the significance of the difference between the averages of the experimental group and the control group, and this significance is at the level of 0.01 in the level of understanding. The following is a comparison between the two groups at the level of application.

It is evident from the Table VI, that there are significant differences at a level of significance (0.05). This is evident from the value of $t$, as the calculated value of $t$ (2.194) is greater than the tabular $t$. This indicates that the difference between the experimental and control group is a fundamental difference.

It is evident from the foregoing that the experimental group outperformed the control group in the post application, and thus the assumption of the first research is accepted.

The results of the current study are consistent with the results of the study of [13], [3], [6], and [14], and differed in terms of the sample with the study of [3] and the [20] and . [19].

The previous results related to the first hypothesis can be interpreted as follows:

The results indicated that there is a statistically significant difference between the mean scores of the experimental group and the control group students in the post application of the cognitive achievement test in favour of the experimental group, who learned using the strategy of inverse separation, compared to the control group that learned by the usual method, and this indicates that the use of the reverse separation strategy had the effect of increasing academic achievement in English language subject for eighth grade students.

This result may be attributed to the lessons prepared for students (outside the classroom) and to the use of the reverse classroom strategy, which helped to invest the time of direct meeting in the classroom and exploited it to accomplish all the educational activities and tasks to be achieved, and this in turn enriched the students 'learning of the research sample, which resulted in to develop knowledge and thus raise the level of achievement.
It is also possible to explain this result to the fact that the use of the reverse separation strategy has found approval and acceptance from the research sample because they learned in a new interesting and enjoyable method which raised their enthusiasm and their desire to learn better and thus increased their achievement.

The second hypothesis test and its text: There is a statistically significant difference at the level of significance $(0.05)$ between the mean scores of the experimental group and the control group students in the post application of the trend scale in favour of the experimental group.

To answer and test the validity of this hypothesis, (T) test was used for independent samples to find the difference between the averages of the experimental and control group in the measure of the trend towards using the strategy of inverse separation and to find out whether these differences are significant or not. The following are the averages and standard deviations of the experimental and control group and the value of $\mathrm{T}$.

The Table VII shows the big difference between the averages of the experimental group and the control group in favour of the experimental group, where the difference between them was 36.52 , and the value of $t$ in the total of the scale was 13.656 and this value is a function at the level of (0.01). The trends of the experimental group are the direction of the reverse separation strategy compared to the control group that was taught using traditional teaching methods, and this means accepting the assumption of the second research. [5] and it differed in terms of the sample with the study of [3] and the study. [19].

The previous results related to the second hypothesis can be interpreted as follows: The results indicated that there was a statistically significant difference between the mean scores of the experimental group and the control group students in the post application of the trend scale in favour of the experimental group, and this indicates that the use of the inverse separation strategy had an effect on the development of students 'attitude towards it. This result may be attributed to the fact that the use of multimedia from audio-visual means through video clips, educational flashes and images, which has the effect of engaging more than one sense in perceiving concepts, stimulating their thinking and retaining them for a longer period than the period of students in the traditional group learning, which contributed to improving and developing students' orientation towards using the reverse separation strategy. Perhaps the teamwork that is characterized by the reverse separation strategy is one of the advantages that have contributed to reaching this result, as it embodies the feeling of belonging to cooperative work and self-confidence, which in turn contributes to increasing the motivation that is among all students when starting to achieve success by completing the required tasks and activities. Positive success for some students is transmitted to the rest of the students, even the weak ones, to strive for all of them, exerting their utmost effort in completing the tasks and activities required of them, which greatly contributed to improving and developing students' tendency towards using the reverse classroom strategy. 
TABLE III. RESUlts OF THE T-TEST IN THE POST APPLICATION OF THE EXPERIMENTAL AND CONTROL GROUP IN TOTAL ACHIEVEMENT IN ENGLISH LANGUAGE

\begin{tabular}{|c|c|c|c|c|c|c|c|}
\hline \multicolumn{3}{|l|}{ T-test } & \multirow{2}{*}{ DS } & \multirow{2}{*}{$\mathbf{M}$} & \multirow{2}{*}{$\mathbf{N}$} & \multirow{2}{*}{ The group } & \multirow{2}{*}{$\begin{array}{l}\text { Parts } \\
\text { the test }\end{array}$} \\
\hline Indication & DF & $T$ value & & & & & \\
\hline \multirow{2}{*}{0.01} & \multirow{2}{*}{48} & \multirow{2}{*}{5.162} & 4.7003 & 19.4800 & 25 & Experimental & \multirow{2}{*}{ Total Summation } \\
\hline & & & 3.5473 & 13.4000 & 25 & control groups & \\
\hline
\end{tabular}

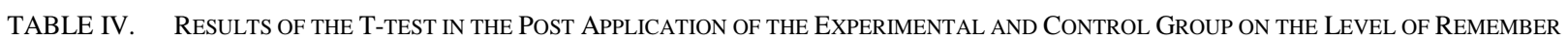

\begin{tabular}{|c|c|c|c|c|c|c|c|}
\hline \multicolumn{3}{|l|}{ T-test } & \multirow{2}{*}{ DS } & \multirow{2}{*}{ M } & \multirow{2}{*}{$\mathrm{N}$} & \multirow{2}{*}{ The group } & \multirow{2}{*}{$\begin{array}{l}\text { Level } \\
\text { the test }\end{array}$} \\
\hline Indication & $\mathrm{DF}$ & $\mathrm{T}$ value & & & & & \\
\hline \multirow{2}{*}{0.01} & \multirow{2}{*}{48} & \multirow{2}{*}{5.162} & 3.4278 & 9.000 & 25 & Experimental & \multirow{2}{*}{ Remembe } \\
\hline & & & 1.8947 & 5.5600 & 25 & control groups & \\
\hline
\end{tabular}

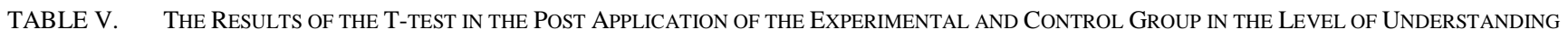

\begin{tabular}{|l|l|l|l|l|l|l|l|}
\hline \multicolumn{2}{|l|}{ T-test } & \multirow{2}{*}{ DS } & M & N & The group & $\begin{array}{l}\text { Level } \\
\text { the test }\end{array}$ \\
\cline { 1 - 7 } Indication & DF & T value & & 2.0066 & 6.1200 & 25 & Experimental \\
\cline { 2 - 6 } 0.01 & \multirow{2}{*}{48} & 2.664 & 1.6906 & 4.7200 & 25 & control groups & Understanding \\
\hline
\end{tabular}

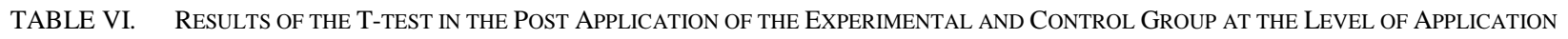

\begin{tabular}{|c|c|c|c|c|c|c|c|}
\hline \multicolumn{3}{|l|}{ T-test } & \multirow{2}{*}{ DS } & \multirow{2}{*}{$\mathbf{M}$} & \multirow{2}{*}{$\mathbf{N}$} & \multirow{2}{*}{ The group } & \multirow{2}{*}{$\begin{array}{l}\text { Level } \\
\text { the Test }\end{array}$} \\
\hline Indication & DF & T value & & & & & \\
\hline \multirow{2}{*}{0.05} & \multirow{2}{*}{48} & \multirow{2}{*}{2.194} & 0.9345 & 4.0400 & 25 & Experimental & \multirow{2}{*}{ Applicatior } \\
\hline & & & 1.4583 & 3.2800 & 25 & control groups & \\
\hline
\end{tabular}

TABLE VII. T-TEST RESUlts IN THE Post APPLICATION OF THE TREND SCALE TOWARDS USING THE REVERSE SEPARATION STRATEGY FOR THE EXPERIMENTAL AND CONTROL GROUPS

\begin{tabular}{|l|l|l|l|l|l|l|l|}
\hline indication & DF & T value & DS & M & N & The group phrase \\
\hline \multirow{2}{*}{0.01} & \multirow{2}{*}{48} & \multirow{2}{*}{13.656} & 9.70172 & 122.0400 & 25 & Experimental \\
\cline { 3 - 6 } & & 9.20199 & 85.5200 & 25 & Total \\
\hline
\end{tabular}

\section{RECOMMENDATION}

In light of the findings of the current research, the following recommendations can be made:

- Making use of the standards and the proposed educational model in the current research in the field of learning the English language.

- The application of multimedia programs in using the flipped learning strategy to raise the level of students in the basic stage in academic achievement.

- Expanding the application of e-learning and blended learning to improve students 'attitudes towards using the flipped learning strategy to learn the English language subject.

- Holding training courses for teachers on using the reverse learning strategy.
A. Implications

1) Studying the effect of using interactive multimedia programs in the flipped classroom on the development of achievement and the trend towards e-learning among students in various disciplines and at various academic levels.

2) Study the extent of the needs of educational institutions in the Hashemite Kingdom of Jordan for the material and scientific requirements to create a mirrored e-learning system.

3) A comparative study between the role of students at the secondary level in the traditional class and the flipped class in the English language subject.

\section{ACKNOWLEDGMENT}

The author is grateful to the Middle East University, Amman, Jordan for the financial support granted to cover the publication fee of this research article. 


\section{REFERENCES}

[1] Abdul Latif, Sally. (2016). The effect of using the flipped learning strategy on developing the cognitive aspect and creative thinking skills in the physical education lesson among students of the College of Physical Education. Unpublished MA thesis, Tanta University, Egypt.

[2] Abu Fayed, Ahmad. (2017). The effectiveness of a proposed program based on the flipped classrooms for the development of achievement in the course of teaching the principles of mathematics and directions towards the inverted classrooms for basic education students at AlAzhar University in Gaza. Unpublished MA thesis, Al-Azhar University, Gaza.

[3] Al-Blassi, Rabab (2015). The effect of the "learning flipped" strategy on developing the skills of the electronic operations course for students of the Diploma in Management of Learning Centres at the University of Hail. MA Thesis, University of Hail.

[4] Al-Dossary \& al-Massad. (2017). The effectiveness of applying the flipped class strategy to academic achievement to learn programming in a computer and information technology course for first-grade secondary students. International Journal of Educational Research, 41 (3), 5-30.

[5] Al-Rawaili \&Al-Talfah. (2018). The effect of using the flipped learning strategy on developing self-organized learning skills among intermediate second students in the subject of social and national studies in Saudi Arabia. Journal of the Islamic University for Educational and Psychological Studies. 28 (1), 617-646, Palestine.

[6] Bisharat, Lina. (2017). The effect of the flipped learning strategy on achievement and mathematical self-concept among tenth grade students in Jericho governorate. MA thesis, An-Najah National University, Palestine.

[7] Caliph \& Mutawa. (2015). Effective Teaching Strategies. Riyadh: AlMutanabi Library, Dammam.

[8] Ismail, Meroe. (2015). The effectiveness of using flipped learning in geography to develop geographical research skills among secondary school students. Educational Association for Social Studies, (75), 35218 .

[9] Othman, Heba. (2016). The effect of the flipped learning strategy on the achievement of students of the seventh grade in basic sciences and their attitudes towards science. Unpublished MA thesis, Yarmouk University, Jordan.

[10] Shorman, Atef. (2015). Blended learning and flipped learning. Amman: House of the March.

[11] Al-Duraibi, vows. (2016). Attitudes and perceptions of university students about the application of the flipped classroom in higher learning. Arab Research in the Fields of Specific Education, (3), 255276.

[12] Al-Muhtadi \&Abu Omar. (2017). The degree to which the second-grade students possess some basic speaking skills in light of the educational content. Al-Hussein Bin Talal University Research Journal, 3 (1), 97108.

[13] Al-Zahrani, Abdul-Rahman. (2015). The Effectiveness of the Flipped Classroom Strategy in the Development of the Level of Achievement of a Sample of Education Students at King Abdul Aziz University in Saudi Arabia, Journal of the College of Education at Al-Azhar University, 1 (68), 5-40.

[14] Qatash, Manal. (2018). The effect of using a flipped learning strategy on achievement and cognitive retention in teaching mathematics skills for second-grade students. Unpublished MA thesis, Middle East University, Amman.

[15] Sabati, Abbas. (2016). Flipped learning: where and when to apply? Alaulka Publishing Network.

[16] Soman, Ahmad (2006). Building an educational program using multimedia and testing its impact on developing speaking and writing skills of primary school students in Jordan, unpublished $\mathrm{PhD}$ thesis, Amman Arab University for Graduate Studies, Amman Jordan.

[17] Tuwayi, Ahmed. (2017). The effectiveness of the flipped learning strategy in the academic achievement of the critical thinking skills course among students of the University of Science and Technology, Aden Branch. The International Journal of Specialized Education, 6 (9), 49-62.

[18] Gerald, O. (2014). "The Flipped Classroom Model for College Algebra: Effects on student Achievement", phD thesis, University of Colorado.

[19] Sengel, E. (2014). Using the "Flipped classroom" to enhance physics achievement of the prospective teacher impact of flipped classroom model on physics course. Journal of the Balkan Tri biological Association, 20(3), 488- 497.

[20] Strayer, J (2007). The effects of the classroom flip on the learning environment: a comparison of learning activity in a traditional classroom and a flip classroom that used an intelligent tutoring system. (Unpublished Columbus: Doctoral Dissertation), Ohio State University.

[21] Qawaqneh, H., Ahmad, F. B., \& Zraiqat, A. (2021, July). The Effect of Using Cyber Hunt Strategy on Developing the Mathematical Academic Achievement for Jordanian Universities Students. In 2021 International Conference on Information Technology (ICIT) (pp. 549-552). IEEE. 